\title{
Schöne Wimpern, volle Lippen
}

Medipharma cosmetics bietet mit seinen Pflegeserien natürliche Pflege für alle Ansprüche. Mit dem Launch von zwei neuen Beautyhelfern erweitert medipharma cosmetics jetzt sein Beauty-Angebot in der Apotheke. Das pure Serum aus dem Wimpern-Booster stimuliert das natürliche Wachstum der Wimpern. Es stärkt die Haarwurzel, erhöht die Anzahl der Wimpern, verleiht Geschmeidigkeit und gesunden Glanz. Koffein regt die Durchblutung an und fördert so das Haarwachstum, Hyaluronsäure lie- fert Feuchtigkeit, sorgt für Geschmeidigkeit und ein gesundes Aussehen der Wimpern, Panthenol beruhigt und pflegt die empfindliche Haut des Augenlids und versorgt den Haarfollikel mit Feuchtigkeit.

Quervernetzte Hyaluronsäure in der Hyaluron-Lippen-Volumenpflege glättet die Haut mit Sofort-Effekt, bindet Feuchtigkeit und füllt so kleine Fältchen in der Lippenhaut auf. Der „Kiss-Me-Quick“Booster regt - im Zusammenspiel mit einem weiteren Extrakt - die Kollagensyn-

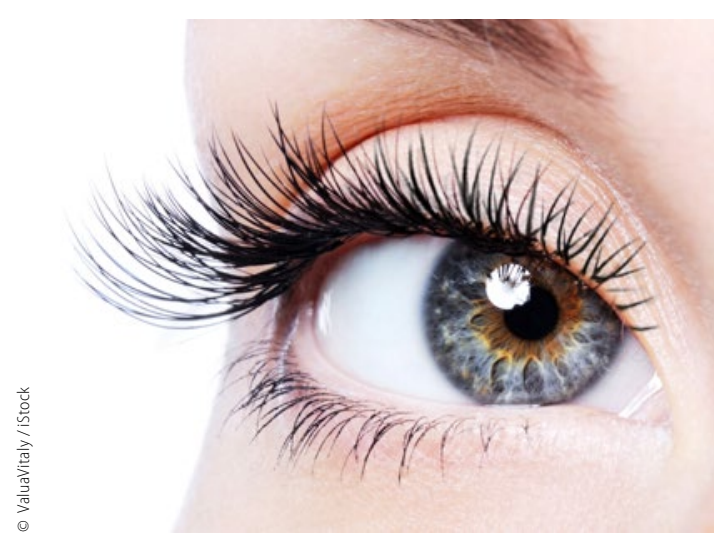

these an, verleiht den Lippen Geschmeidigkeit und einen volleren Look. red

Nach Informationen von Dr. Theiss Naturwaren

\section{UV-Filter reichen nicht}

\section{Haut auch vor sichtbarem Licht schützen}

Moderne Sonnenschutzprodukte enthalten UV-A- und UV-B-Filter. Damit schützen sie die Zellen der Epidermis und teilweise auch Dermis vor strahleninduzierten DNA-Schädigungen. Die Produktion von freien Radikalen, wie den reaktiven Sauerstoffspezies (ROS), wird unterbunden.

Doch nicht nur UV-Strahlung provoziert Sonnenschäden: Neuere Untersuchungen zeigen, dass auch der sichtbare Teil des Lichtes (VIS) ROS und Interleukin-1 (IL-1) sowie Matrix-Metalloprotease-1 (MMP-1) induziert. Damit trägt vor allem der blau-violette VIS-Anteil noch stärker als UV-A zu Hyperpigmentierung und Hautalterung bei - und das bis tief in die Schichten der Dermis, resümierte Prof. Dr. Thierry Passeron, Nizza, Frankreich. Vor allem Menschen mit dunklerer Haut (Hauttyp $\geq$ III) scheinen demnach von einem zusätzlichen Schutz gegen sichtbares Licht zu profitieren.

Aktive Zusatzstoffe bilden eine Barriere gegen VIS-induzierte ROS. Eines dieser sogenannten Actives ist Licochalcone A (LicA), ein Phenol aus der chinesischen Süßholzwurzel (Glycyrrhiza inflata). In vitro konnten in mit LicA behandelten Zellen nach UV-A-Bestrahlung geringe-
Filler jetzt auch mit Lidocain erhältlich

\section{Kontur mit Komfort}

Der Volumen- und Lifting-Filler Radiesse ${ }^{\circledast}$ ist seit September 2016 auch in Deutschland mit integriertem $0,3 \%$ Lidocain und wahlweise ohne Lokalanästhetikum verfügbar.

Der Lidocain-Gehalt von $0,3 \%$ reduziert den Schmerz des Patienten deutlich und steigert so dessen Zufriedenheit [Schachter D et al. Drugs Dermatol. 2016;15:1005-10]. Zudem überzeugt der Filler mit einem geringen Auspressdruck für eine noch komfortablere Anwendung. Der Dreifach-Effekt ermöglicht eine effektive Faltenkorrektur, ein sofort sichtbares Lifting sowie optimale Konturierung des unteren Gesichtsdrittels durch gezielten Volumenaufbau. Angenehmer Zusatzeffekt: Durch die Stimulation des natürlichen körpereigenen Kollagenaufbaus kann die Hautqualität nachhaltig verbessert werden. Seit 2006 besitzt der Filler als einziges Produkt auf Kalzium-Hydro- re ROS-Konzentrationen gemessen werden, da LicA die Expression von zellprotektiven, antioxidativen und antiinflammatorischen Enzymen wie dem Nuclear-factor-erythroid-2-related-factor-2 (Nrf2) aktiviert. Anhand von UV-Ainduzierter Lumineszenz konnten auch in vivo Anhaltspunkte für weniger oxidative Prozesse durch LicA-Applikation gewonnen werden. Die Produkte der Eucerin ${ }^{\circledast}$ Sun-Reihe enthalten LicA und schützen so vor UV- und VIS-induzierten Zellschäden, erläuterte Dr. Ludger Kolbe, Chef-Wissenschaftler für Photobiologie bei Beiersdorf R\&D, Hamburg.

Alexandra Ullrich

Satellitensymposium „The Visible Progress In Medical Sun Protection" im Rahmen des 25. EADV-Kongresses, Wien, 29.9.2016; Veranstalter: Beiersdorf
xylapatit-Basis die Zulassung von der amerikanischen Gesundheitsbehörde FDA, seit 2015 auch für Radiesse ${ }^{\circledast}$ Lidocaine.

Mit mehr als 200 klinischen Studien und wissenschaftlichen Publikationen, die dem Dermalfiller das überzeugende Sicherheitsprofil und die gute Effektivität an mehr als 5.000 Patienten bestätigen, gehört der Filler zu den best untersuchten Dermalfillern weltweit [Loghem JV. J Clin Aesthet Dermatol 2015; 8:38-49]. Seit der Einführung in Europa im Jahr 2004 wurden rund sechs Millionen Ästhetikbehandlungen mit dem Filler durchgeführt.

red

Nach Informationen von Merz Pharmaceuticals 